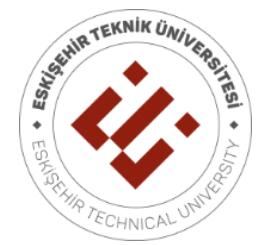

ESKISSEHİR TECHNICAL UNIVERSITY JOURNAL OF SCIENCE AND TECHNOLOGY A- APPLIED SCIENCES AND ENGINEERING

2019, Vol: 20, pp. 19 - 23, DOI: 10.18038/estubtda.630439

\title{
EFFECT OF THE SYNTHESIS TEMPERATURE OF POLYCARBOXYLATE-BASED SUPERPLASTICIZER ON THE PERFORMANCE OF CONCRETE
}

\author{
Melih ÖZDURAN, Zeynep ÖZSERÇE HASTE, Sevil ÇETINKAYA GÜRER* \\ Chemical Engineering Department, Engineering Faculty, Sivas Cumhuriyet University, Sivas, Turkey
}

\begin{abstract}
Good quality Polycarboxylate superplasticizers (PCEs) production is increasingly important due to development of the construction industry in the world. In this study, modified PCEs were synthesized via free-radical polymerization of Translated Polyethylene Glycol (TPEG), Thioglycolic Acid (TGA) and Acrylic Acid (AA), in the presence of initiator and chain transfer agent according to molecular structure design principle in different initiatory temperatures $\left(40\right.$ and $\left.60{ }^{\circ} \mathrm{C}\right)$. The effects of PCEs synthesized at different temperatures on the concrete such as water cutting, workability and compressive strength of 7 and 28 days' have been examined. Fourier transform infrared spectroscopy (FTIR) was used for structural characterization.
\end{abstract}

Keywords: Polycarboxilate, Concrete, Compressive strength, Radical polymerization

\section{INTRODUCTION}

In the recent years, with the development of high performance concrete technology, the need for various chemical admixtures as concrete additives increases. Chemical admixture plays an important role in concrete, it could reduce water consumption and increase the compressive strength of concrete. Thus, researchers have focused on the development and production of concrete additives [1-3]. Some chemical admixtures can help concrete to achieve some special performance such as high slum pretention, water reducing rate, high flowing and self-compacting [4]. PCEs are one of the most important of these chemical additives. The workability of Polycarboxylate superplasticizer (PCE) is a significant factor to achieve high performances in the construction sector [5]. Generally, one of the most critical effects on the adaptation between PCE and cement is its structure, which depends on the preparation conditions such as reaction temperature and time, feeding time of solutions, and kind of monomer. PCEs are formed of polyethylene oxide (PEO) side chains grafted onto an anionic polymer backbone which has two main parts: carboxylic groups as the backbone and polyethylene oxide as the side chains [1]. The PEO side chains excite a steric hindrance effect between the cement particles suspended in water [6]. Although the effect of PCEs on concrete has been investigated in some studies [7,8], effect of the synthesize temperature of PCEs on concrete performance is very limited [9].

In this study, PCEs were synthesized by radical polymerization and effect of the synthesize temperature of PCEs on concrete was investigated.

\section{MATERIALS AND METHOD}

\subsection{Experimental}

\subsubsection{Raw materials}

Tresylated polyethylene glycol (TPEG) (OXAB-501, with Mw 2400) was supplied by Liaoning Oxiranchem Inc. Acrylic acid (AA), Thioglycolic acid (TGA), hydrogen peroxide $\left(\mathrm{H}_{2} \mathrm{O}_{2}\right)$, ascorbic acid

*Corresponding Author: cetinkaya.sevil@gmail.com

Received: 01.10.2019 Published: 16.12.2019 
(Vc) were purchased from Fluka, Merc, Aldrich, Zag respectively. The cement used in this study was an ordinary Portland cement (CEM II/A-LL-42.5/R), supplied by Sivas(Turkey) Votorantim cement plant.

\subsubsection{Synthesis of PCEs}

Two polymers designed PCE-40 and PCE-60 are synthesized at 40 and $60{ }^{\circ} \mathrm{C}$ of initial temperature, respectively. TPEG was dissolved in distilled water, when the temperature rises to initial value. AA aqueous solution, and TGA and VC aqueous solution were added drop-wise into the reaction mixture separately (Figure 1). All solution was mixed at $400 \mathrm{rpm}$ until dissolved. The polymerization reaction was carried out in an aueous medium for 4 hours using hydrogen peroxide as an initiator. Finally, the aqueous PCs solution was cooled to ambient temperature.

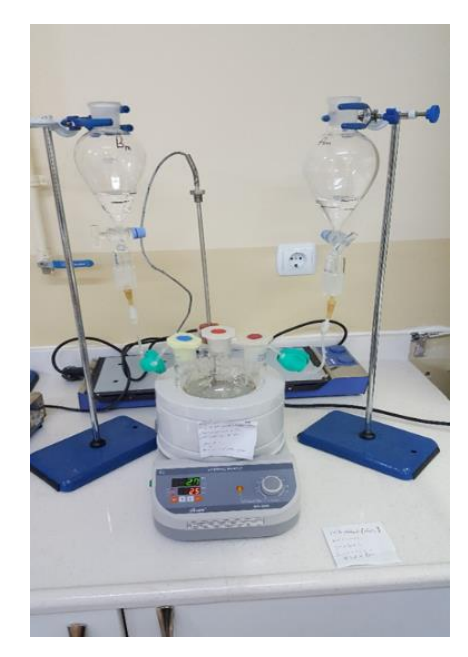

Figure 1. Experimental system

The chemical structure and schematic of the PCE are shown in Figure 2.<smiles>CCC(CC(C)(C)C)C(C)CCOCCOO</smiles>

Figure 2. Molecular structure of PCE

\section{RESULT AND DISCUSSION}

\subsection{Determination of synthesis temperature of PCE}

The effects of PCEs synthesized at different temperatures on the concrete performance are shown in Table 1. Two series of synthesized PCEs(PCE-40 and PCE-60) were used in this study. The measurements of concrete mixtures slump with the equal amount of PCE-40 and PCE-60 were conducted the initial concrete slump rapidly by using slump cone after the mixing of concrete. After 
finished the determination of initial concrete slump, the mixtures were placed under condition of air temperature for $30 \mathrm{~min}$ and tested the concrete slump immediately (Figure 3)
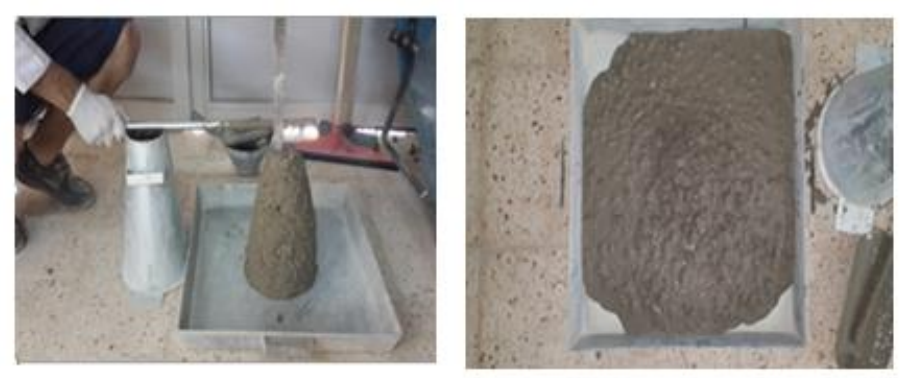

Figure 3. Slump test of concrete

As shown in Table 3, no change was observed in slump and compressive strength of the concrete values which is used PCEs synthesized at different temperatures. In most studies, radical polymerization of PCEs was carried out under $30-80{ }^{\circ} \mathrm{C}$ [2-9]. Quantity of heat is needed during the polymerization reaction. It is more convenient to work at low temperatures to save energy.

Table 1. The effects of PCEs synthesized at different temperatures on the concrete slump and compressive strength

\begin{tabular}{ccc}
\hline Synthesize Temperature of PCE, ${ }^{\circ} \mathrm{C}$ & 40 & 60 \\
\hline Initial slump, cm & 15 & 15 \\
\hline After 30 min slump, cm & 8 & 8 \\
\hline compressive strength of concrete (7d), MPa & 29.14 & 29.93 \\
\hline compressive strength of concrete (28d), Mpa & 35.18 & 36.96 \\
\hline
\end{tabular}

(a)

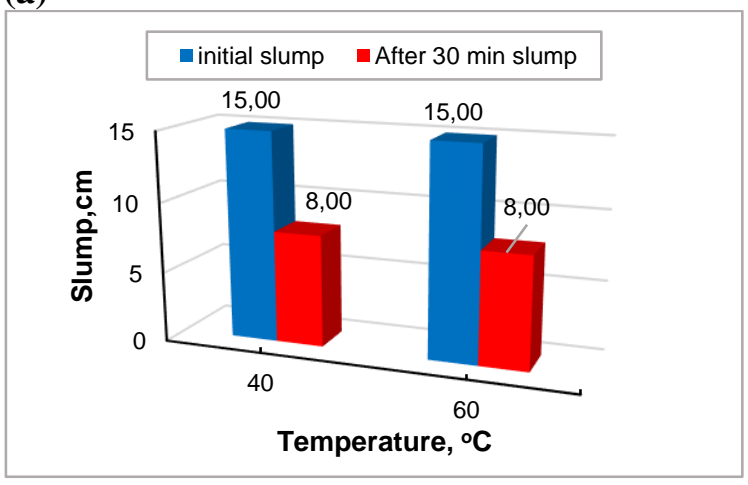

(b)

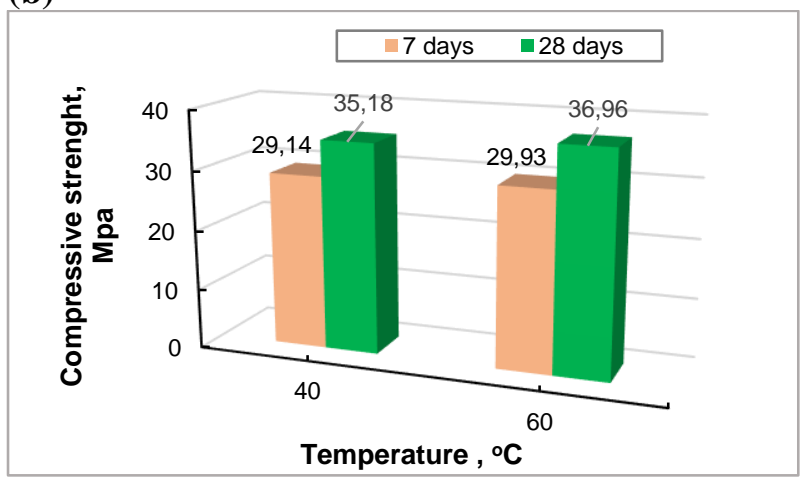

Figure 4. The effects of PCEs synthesized at different temperatures on the Concrete(a) slump and (b) compressive strength

\subsection{FTIR Spectrum of PCEs}

The infrared spectrum for the PCEs synthesized at different temperatures are given in Figure $5.1093 \mathrm{~cm}^{-}$ ${ }^{1}$ is the absorption peak of C-O-C ether linkage on long-chain of polyoxyethylene of polyether side chain [5]. The peak at $1648 \mathrm{~cm}^{-1}$ is assigned the presence of carboxylic acid. The peak at $3306 \mathrm{~cm}^{-1}$ is the stretching vibration band of $\mathrm{C}-\mathrm{H}$. It was observed that there was no change in the structure of PCEs synthesized at different temperatures from FTIR spectra (Figure 5.). Thus, it can be say that both PCEs have similar functional groups. 


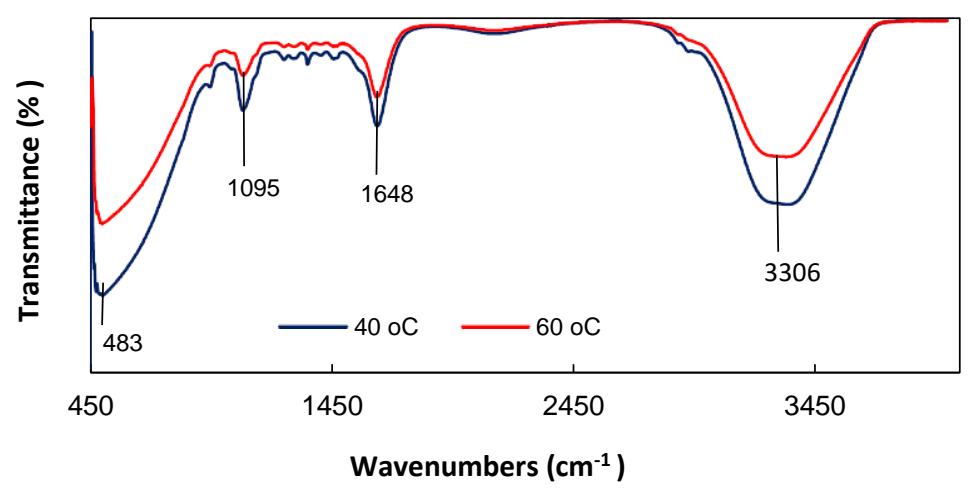

Figure 5. FTIR spectrum of polycarboxylates (PCEs) synthesized at different temperatures

\section{CONCLUSION}

In this study, PCEs were successfully synthesized in different initiatory temperatures $\left(40\right.$ and $\left.60{ }^{\circ} \mathrm{C}\right)$ by free radical polymerization method. The effects of synthesized PCEs on concrete performance were tested. It is observed that both PCEs have the same effect on compressive strength, consistency protection and workability of the concrete. Therefore, low temperature can be study to synthesize of PCE. Our future plan is to study under room temperature for preparing of PCEs because of saving energy and reducing the pollution of the environment.

\section{ACKNOWLEDGEMENTS}

This study was supported by Sivas Cumhuriyet University Scientific Research Projects (CÜBAP), project number as M744.

\section{REFERENCES}

[1] Kong F-r, Pan L-s, Wang C-m, Zhang D-1, Xu N. Effects of polycarboxylate superplasticizers with different molecular structure on the hydration behavior of cement paste. Construction and Building Materials 2016; 105: 545-553.

[2] Huang H, Qian C, Zhao F, Qu J, Guo J, Danzinger M. Improvement on microstructure of concrete by polycarboxylate superplasticizer (PCE) and its influence on durability of concrete. Construction and Building Materials 2016; 110: 293-299.

[3] Liu X, Guan J, Zheng Y, Wang1 Z, Ren X. Synthesis of High Performance Polycarboxylate Superplasticizer through Redox Initiation System and its Application in Concrete. Key Engineering Materials 2016; 723: 681-686.

[4] Liu X, Wang Z, Zheng Y, Cui S, Lan M, Li H, Zhu J, Liang X. Preparation, Characterization and Performances of Powdered Polycarboxylate Superplasticizer with Bulk Polymerization. Materials 2014; 7: 6169-6183.

[5] Qian S, Jiang H, Ding B, Wang Y, Zheng C, Guo Z. Synthesis and performances of polycarboxylate superplaticizer with clay-inerting and high slump retention capability. Materials Science and Engineering 2017; 182: 1-12. 
[6] Ng S, Plank J. Interaction mechanisms between Na montmorillonite clay and MPEG-based polycarboxylate superplasticizers. Cement and Concrete Research 2012; 42: 47-854.

[7] Liua X, Guana J, Laia G, Zhengb Y, Wanga Z, Cuia S, Lana M, Li H. Novel designs of polycarboxylate superplasticizers for improving resistance in clay-contaminated concrete. Journal of Industrial and Engineering Chemistry 2017; 55: 80-90.

[8] Tan H, Li X, Liu M, Ma B, Gu B, Li X. Tolerance of cement for clay minerals: effect of side-chain density in polyethilene oxide (PEO) superplasticizer additives. Clays and Clay Minerals 2016; 64: $732-742$.

[9] Wang J, Zheng G, Yuan M, Sun C, Bi Y. Effect of the initial temperature on the water-reducing performance of polycarboxylate-based superplasticizers. International Conference on Materials, Environmental and Biological Engineering (MEBE 2015), 213-217. 